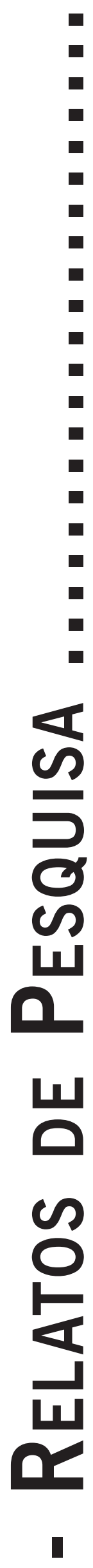




\title{
EXPERIÊNCIAS DE ESTUDANTES DE PSICOLOGIA EM OFICINAS DE DESENVOLVIMENTO DA ESCUTA
}

\author{
Experiences of Psychology Students in Listening Development Workshops \\ Experiencias de Estudiantes de Psicología en Talleres de Desarrollo de la Escucha
}

\author{
Aíla Matos Dourado \\ CRistiane Alves Quirino \\ Monzitti Baumann de Almeida Lima \\ SHIRLEY MaCÊDo VIEIRA DE MELo
}

\begin{abstract}
Resumo: Essa pesquisa insere-se na interface entre a Psicologia Organizacional e do Trabalho (POT) e a Psicologia Clínica. O objetivo geral foi compreender como se deram as experiências de estudantes de psicologia da Universidade Federal do Vale do São Francisco (Petrolina/PE), que participaram de oficinas de desenvolvimento da escuta. Especificamente, pretendeu-se descrever os resultados obtidos nos processos vivenciados nas oficinas; identificar as competências desenvolvidas e descrever os ganhos de aprendizagem obtidos. Consistiu de uma pesquisa qualitativa de cunho fenomenológico. Participaram 19 graduandos que, respondendo a entrevistas abertas individuais com pergunta disparadora, discorreram livremente sobre suas experiências. Os resultados apontaram para alcances terapêuticos, pois as oficinas, além de repercutirem na vida pessoal e acadêmica de cada sujeito, permitiram a sensibilização para o cuidado de si e do outro. Os estudantes, também, reconheceram a escuta clínica como uma ferramenta indissociável ao trabalho do psicólogo. As principais competências desenvolvidas foram: conhecimentos sobre a prática psicológica clínica, diferenciação da escuta clínica da comum, habilidades interpessoais, sigilo e autocuidado. Concluiuse, principalmente, que oficinas de desenvolvimento da escuta, por favorecerem a apropriação de singularidade e promoverem novos modos de subjetivação, podem constituir uma modalidade prática clínica em POT em uma instituição de ensino superior em psicologia.
\end{abstract}

Palavras-chave: Escuta; Formação do psicólogo; Psicologia organizacional e do trabalho; Desenvolvimento de competências; Psicologia clínica.

\begin{abstract}
This research is part of the interface between Organizational and Work Psychology (OWP) and Clinical Psychology. The overall objective was to understand how the experiences happened to psychology students at the Universidade Federal do Vale do São Francisco (Petrolina/PE), who participated in workshops on listening development. In particular, it was sought to describe the results obtained in the processes experienced in the workshops; identifying the developed competences and describing the learning gains achieved. The study consisted of a qualitative research of phenomenological nature. Nineteen undergraduates took part, responding to open interviews with starter question, and discussed freely about their experiences. The results indicated therapeutic ranges, as the workshops, as well as reverberating in the personal and academic life of each subject, allowed raising awareness for the care for oneself and for the others. Students recognized the clinical listening as an inseparable tool to the work of psychologist. The core competencies developed were: knowledge about clinical psychological practice, differentiation from the common clinical listening, interpersonal skills, confidentiality and self-care. It was concluded that Listening Development workshops, by favoring the appropriation of uniqueness and fostering new modes of subjectivation, may be a modality in clinical practice in OWP in psychology degree.
\end{abstract}

Keywords: Listening; Psychologist training; Organizational and work psychology; Competence development; Clinical psychology.

Resumen: El objetivo general ha sido comprender como se dieron las experiencias de estudiantes de psicología de la Universidade Federal do Vale do São Francisco (Petrolina/PE) que participaron de los talleres de desarrollo de la escucha. Especificamente se ha pretendido describir los resultados obtenidos en los procesos vividos en dichos talleres; identificar las competencias desarrolladas y describir los aumentos de aprendizaje obtenidos. Ha consistido en un trabajo cualitativo de cuño fenomenológico. Han participado 19 alumnos que, respondiendo a entrevistas abiertas individuales con pregunta disparadora hablaron libremente sobre sus experiencias. Los resultados han apuntado para los alcances terapéuticos, pues los talleres, además de repercutir en la vida personal y académica de cada sujeto, han permitido la sensibilización para el cuidado de si mismo y de los otros. Los estudiantes también reconocieron la escucha clínica como una herramienta indispensable al trabajo del psicologo. Las principales competencias desarrolladas fueron: conocimientos sobre práctica psicológica clínica, diferenciación de la escucha clínica de la común, habilidades interpersonales, sigilo y autocuidado. Se concluye, principalmente, que talleres de desarrollo de la escucha, por favorecer la apropiación de singularidades y promover nuevos modelos de subjetivación, pueden constituir una modalidad práctica clínica en POT en una institución de enseñanza superior en psicología.

Palabras-clave: Escucha; Formación del psicólogo; Psicólogía organizativa y del trabajo; Desarrollo de competencias; Psicología clínica. 


\section{Introdução}

A Resolução CNE/CES No 5, de 15 de março de 2011 (BRASIL, 2011), que revoga a Resolução CNE/CES No 8 , de 7 de maio de 2004, instituiu as Diretrizes Curriculares Nacionais para os Cursos de Graduação em Psicologia no Brasil, orientando princípios, fundamentos, condições de oferta e procedimentos para o planejamento, implementação e avaliação destes cursos. Elas apontam para a necessidade do psicólogo graduado ser capaz de diagnosticar, avaliar e atuar em problemas humanos de ordem cognitiva, comportamental e afetiva; além de coordenar e manejar processos grupais; atuar inter e multiprofissionalmente; realizar orientação, aconselhamento psicológico e psicoterapia; levantar questões teóricas e de pesquisa; e gerar conhecimentos a partir de sua prática profissional. Para isso, elencam um conjunto de competências a serem desenvolvidas pelo curso e as habilidades nas quais essas competências se apoiam.

No artigo $3^{\circ}$ (p. 1), é referido que a formação do psicólogo deve estar fundamentada em alguns compromissos, dentre eles a capacitação e o aprimoramento contínuos. Além disso, o texto do CNE/CES destaca que algumas das habilidades que dão suporte às competências básicas são as de "descrever, analisar e interpretar manifestações verbais e não verbais como fontes primárias de acesso a estados subjetivos" (p. 4).

Sobre o dever das atividades acadêmicas, as Diretrizes também apontam proporcionar subsídios para que as competências, as habilidades e os conhecimentos fundamentais básicos para a prática profissional sejam adquiridos pelos futuros psicólogos. Apesar de não diferenciarmos competências e habilidades, pois acreditamos que as segundas estão inseridas nas primeiras, por estas serem um conjunto de conhecimentos, habilidades e atitudes, entendemos, tal como defendido por Quayle (2010), que qualquer proposta voltada para a formação do psicólogo deve ser elaborada tomando por base estas diretrizes. Além disso, sustentamos que todas as competências elencadas nas Diretrizes não estão apartadas da escuta clínica, pois esta faz parte, dentre outras, das habilidades interpessoais que devem ser desenvolvidas em um curso de Psicologia.

Bandeira, Quaglia, Freitas, Souza, Costa, Gomides e Lima (2006), ao pesquisarem as habilidades interpessoais na atuação do psicólogo, investigaram profissionais do interior de Minas Gerais, que alegaram que seus cursos de graduação não contemplavam a formação dessas habilidades, destacando o ouvir com atenção a fala do outro como a mais importante e menos desenvolvida nas suas graduações. Os profissionais também apontaram outras habilidades necessárias, mas não desenvolvidas na sua formação universitária como eles julgavam ideal: fazer e responder perguntas e expressar empatia; observar no outro expressões verbais relevantes; ajudar o outro a identificar, nomear e expressar seus sentimentos; responder, de forma adequada, perguntas do interlocutor; fazer perguntas importantes de acordo com as condições da interação; fazer relações entre diferentes conteúdos da fala do interlocutor; interpretar a fala do outro; conduzir a direção de uma conversação; reformular com outras palavras o conteúdo da fala do outro e resumir o discurso do outro ao longo de uma conversação. Todas essas habilidades podem ser relacionadas à escuta clínica.

\section{O que chamamos de escuta psicológica clínica}

A escuta psicológica clínica pode ser considerada um dispositivo de cuidado, imprescindível diante das demandas com as quais o psicólogo lida, que são, em sua maioria, advindas de um sujeito que porta certo tipo de sofrimento. Nas relações que estabelece com este outro, o profissional de psicologia transita entre um cuidar e saber de si, a fim de dar conta dos múltiplos sentidos do processo (Lima, 2005).

Lima (2005) destaca que o escutar, ao contrário do ouvir, não se baseia apenas na coleta de sons que chegam aos ouvidos. O escutar perpassa por uma abertura e envolvimento com o outro que fala, ou melhor, diz. Nesse sentido, a escuta clínica na prática psicológica não se caracteriza como uma escuta comum, mas como um ouvir diferenciado, pois quem escuta e quem fala se abrem à experiência alteritária e produzem novos significados que favorecem novos modos de sentir, pensar e agir.

Lembramos, aqui, o que refere Amatuzzi (2008): se o aparelho auditivo estiver em ordem, qualquer pessoa pode ouvir, mas não escutar, ou não ouvir realmente, pois para ouvir realmente é preciso atravessar os sons e ir até o significado que emerge do conteúdo da pessoa que fala. Defendemos, como propõe Heckert (2007), que a escuta clínica não é um saber que possa ser transmitido na forma de conteúdo técnico, mas demanda uma experienciação do sujeito no contato direto com a prática de escutar. É no encontro de sentidos que vai se constituindo a escuta, de modo que esta englobe uma trama maior de saberes e fazeres da psicologia (Lima, 2005).

Também estamos de acordo com Braga, Daltro e Danon (2012), quando nos dizem o quanto é importante que o profissional de psicologia ocupe um lugar específico que propicie a escuta a partir de sua subjetividade implicada nas várias experiências do sujeito, como possibilidade de fazer diferença nas diversas áreas de atuação. Independente da abordagem ou perspectiva a ser seguida, a escuta clínica caracteriza-se principalmente como uma competência da prática do psicólogo que está atrelada ao cuidado (MACÊDO, 2000). Já que essa escuta perpassa pelo cuidado, faz-se necessário que o futuro psicólogo vivencie o processo de se escutar e cuidar de si para poder escutar e cuidar do outro. 


\section{A escuta clínica e a formação graduada do psicó- logo}

No nosso entender, há uma carência do desenvolvimento da escuta clínica nos cursos de graduação em Psicologia. Essa carência se dá, principalmente, porque não se pode ensinar a escutar. Necessário lembrar, aqui, que autores referendados no campo das ciências interpretativas do psiquismo humano, como Sigmund Freud, já eram enfáticos em admitir que a escuta não é algo que se ensina por um ato pedagógico, pela transmissão de conteúdos teóricos a serem aplicados. Neste sentido, não pode ser transmitida enquanto técnica, haja vista que ensinar a escutar é uma tarefa impossível. Escutar se desenvolve na experimentação e se constitui no caminhar da formação como psicólogo (Heckert, 2007).

Heckert (2007) lembra que a maioria dos processos de formação desprezam os saberes e experiências dos aprendizes. Nessa ótica, considera que o cuidado na formação de profissionais de saúde é uma prática que se efetiva no compartilhamento de experiências. Portanto, a escuta se desenvolveria no contexto de cuidado como negociação e construção coletiva, que se constituiria pela reflexão, pensamentos e intervenções mútuas entre sujeitos que compartilham experiências entre si. Assim, somente é possível se pensar a escuta como experimentação, como reinvenção de si e do mundo. Desta feita, o desafio de quem educa é criar modos de ensino de maneira a fomentar a experimentação e a desestabilização das certezas, provocando a formulação de novos problemas, ou melhor, engendrando processos de formação-intervenção. "No processo de formação, torna-se fundamental criar estratégias que permitam escutar as diferenças (...). Afirmar a escuta como experimentação significa indicar as necessidades do outro, com o qual lidamos, que precisam ser incluídas" (Heckert, 2007, p. 10).

Somos da opinião de Coelho e Figueiredo (2004), que as práticas psicológicas se confrontam cada dia mais com a necessidade de reconhecer a alteridade como constitutiva de subjetividades singulares. No entanto, na maioria das vezes, o ambiente acadêmico da graduação em psicologia traz uma carga assaz pesada e rebuscada de teorias que, apesar de serem fundamentais no processo de desenvolvimento profissional, não favorecem um ensino focado no reconhecimento dos desafios práticos do cuidado com o outro, que um graduando de psicologia enfrentará no exercício da profissão. Além disso, nossa experiência em instituições de ensino de Psicologia nos leva a questionar se essa pluralidade teórica se sobressai à prática. Mesmo que busquem atender ao que propõem as Diretrizes Curriculares Nacionais para a formação do psicólogo, vimos observando que a prática é apresentada tardiamente aos estudantes, o que parece dificultar o modo como estes vão posicionar-se futuramente como profissionais de psicologia.
Sabemos que, ao longo da graduação, os estudantes se deparam com momentos em que exercitam a escuta, tais como trabalhos de grupo, atividades em sala de aula ou de campo, projetos de extensão e outros. Contudo, esse modo de escutar pode não estar direcionado à atitude clínica profissional. Sendo assim, a escuta tem-se mostrado como um dispositivo da prática que acaba sendo aprofundado apenas no final do curso, ou nos momentos de estágios profissionalizantes, ou quando os estudantes reconhecem a necessidade de uma psicoterapia (Meira \& Nunes, 2005), e estão prestes a adentrar o mercado de trabalho.

Acreditamos, entretanto, que a escuta clínica, ao ser desenvolvida como uma competência durante a formação graduada do psicólogo, pode ser trabalhada a partir do desenrolar de conhecimentos, habilidades e atitudes. Isso significa que não é necessário apenas o saber, ou seja, os conhecimentos acadêmicos para desenvolver ou sensibilizar a escuta, mas também o saber fazer e o querer fazer, isto é, pôr em prática e estar disponível para isso.

\section{Oficinas de desenvolvimento da escuta: uma ati- vidade a mais na formação do psicólogo}

Considerando que atividades de sala de aula, estritamente acadêmicas, não permitem um aprofundamento da ferramenta da escuta clínica, e que alguns estudantes de Psicologia apenas a experimentam no final do curso, oferecemos na Universidade Federal do Vale do São Francisco (UNIVASF) oficinas de desenvolvimento de escuta aos graduandos. Partimos do princípio de que tais oficinas podem funcionar como capacitação ampliada para estes estudantes, constituindo uma alternativa eficaz ao investimento na carreira e ao futuro ingresso no mercado de trabalho.

Pensamos essas oficinas como essenciais numa graduação em psicologia, pois, lembrando que a formação pode constituir-se como espaço de compartilhamento de experiências, essa seria uma saída para desenvolver a escuta no contexto de graduação do psicólogo, já que, como bem alerta Heckert (2007, p.5): "todo processo de formação se produz no encontro com a alteridade, pois que é um processo de produção de subjetividade".

A atividade se inseria num projeto de extensão na UNIVASF, levado a cabo no primeiro semestre de 2013, que focava a formação do psicólogo e era intitulado "Mapeamento e Desenvolvimento de Competências em Estudantes e Profissionais de Psicologia”. Dentre os objetivos do projeto, as oficinas visavam desenvolver competências em estudantes de diversos períodos, além de oferecer um espaço de escuta e acolhimento aos mesmos. Cada oficina, das três oferecidas, envolvia um máximo de 20 participantes de diferentes períodos do curso, uma docente psicóloga e três trainees, e acontecia semanalmente, durante duas horas, totalizando quatro encontros e oito horas num mês. As trainees, também estudantes do 
curso (duas do terceiro e uma do oitavo período) tinham a função, junto à orientadora, de facilitar os processos conduzidos. Os instrumentos utilizados eram dinâmicas de grupo, dramatizações, músicas, contos, mitos, atividades de colagem e modelagem com argila.

Respaldada teoricamente na psicologia humanista, a oficina de desenvolvimento da escuta tinha por base a aprendizagem significativa - entendida como processo que favorece mudanças intelectuais e vivenciais. Cada encontro era programado a partir do encontro anterior, portanto, cada oficina foi singular e possibilitou vivências e processos diferenciados. Ao longo dos encontros, constatávamos, por um lado, que os participantes se sensibilizavam para uma escuta diferenciada, mobilizavam-se subjetivamente, muitas vezes expressando como aquele momento estava sendo importante para suas vidas e sua formação acadêmica; por outro lado, os trainees, que, mesmo sem ainda terem adentrado os estágios de final de curso, recebiam supervisão antes e após cada encontro, encantavam-se com a possibilidade de praticar a clínica em psicologia, reconhecendo aquele espaço como capacitação para seu futuro profissional.

Este artigo, portanto, nasceu da necessidade de sistematizarmos um saber sobre aquela experiência, apresentando uma pesquisa realizada com os participantes das oficinas, cujo objetivo geral foi compreender como se deram as experiências dos estudantes, tanto os participantes quanto as trainees. Os objetivos específicos foram: descrever os resultados obtidos nos processos vivenciados nas oficinas; identificar as competências desenvolvidas e descrever os ganhos de aprendizagem obtidos.

A pesquisa foi aprovada pelo Comitê de Ética e Deontologia em Pesquisas com Seres Humanos (CEDEP) da UNIVASF, estando registrada pelo número 0010/1406, e transcorreu entre agosto de 2013 e julho de 2014, com recursos do Programa Institucional de Bolsas de Iniciação Científica (PIBIC CNPq/UNIVASF).

\section{Metodologia}

Diante do que se propôs o estudo, adotamos como metodologia a pesquisa qualitativa fenomenológica. Nessa perspectiva, tanto o sujeito investigado quanto o pesquisador estão implicados na construção do conhecimento. Como bem frisa Amatuzzi (2008), o que constitui uma pesquisa fenomenológica é a mesma está voltada para o vivido. Neste sentido, quando um sujeito descreve sua experiência, torna-se possível ao pesquisador compreender os significados atribuídos por alguém ao seu vivido e, a partir disso, construir conhecimento.

Para se conduzir uma pesquisa fenomenológica, é necessário o desenvolvimento de competências técnicas e comportamentais, já que a fenomenologia deve ser pensada como atitude da prática psicológica adotada pelo pesquisador, partindo do pressuposto de que as experi- ências são intersubjetivas e que, nestas, pesquisador e sujeito da pesquisa são parceiros que estão em contato a partir da intencionalidade da consciência (Macêdo \& Caldas, 2013).

Segundo Bicudo e Martins (1989), o que necessariamente caracteriza uma pesquisa fenomenológica é o fato de o pesquisador iniciar interrogando sobre o fenômeno; a situação da pesquisa ser definida pelos sujeitos investigados; o investigador buscar o sentido da experiência para os sujeitos em estudo; e os dados serem concebidos como provenientes das significações resultantes da tematização do sujeito acerca da experiência. Partindo dessa metodologia, escolhemos utilizar a entrevista aberta com uma pergunta disparadora, pois essa técnica faz com que o sujeito se abra para a sua experiência, favorecendo que fale livremente sobre ela, o que ajuda o pesquisador no sentido de compreender e interpretar os seus significados e sentidos.

Os 19 sujeitos da pesquisa foram as três trainees e 16 estudantes que participaram de diferentes oficinas. Convidado para entrevista individual de forma voluntária, cerca de três a seis meses após sua participação naquelas atividades, cada entrevistado assinava o Termo de Consentimento Livre e Esclarecido e depois respondia à pergunta disparadora: "como se deu a sua experiência de participar da oficina de desenvolvimento da escuta?” As entrevistas foram realizadas por duas bolsistas de iniciação científica que compunham a equipe de pesquisa junto à orientadora, e registradas em gravador digital, num tempo máximo de 40 minutos cada, e ocorreram em sala reservada do Centro de Estudos e Práticas em Psicologia (CEPPSI) da UNIVASF.

Após a coleta, foram analisados os dados em cinco passos (baseados em GIORGI, 1985; Macêdo, 2000, 2006; Amatuzzi, 2008):

a) Leitura integral do todo do relato: após transcrição integral de cada relato por uma das bolsistas, ele foi lido por cada membro da equipe de pesquisa quantas vezes fosse necessário para que se alcançasse os significados da experiência;

b) Encontro com as unidades de significado: tendo os objetivos da pesquisa em mente, cada membro da equipe de pesquisa destacou trechos dos relatos que, para ele, foram significativos em relação à experiência investigada;

c) Presentificação do sentido da experiência: de posse das unidades de significado, a equipe de pesquisa buscou encontrar, em um contexto de diálogo, os sentidos da experiência relatada pelos sujeitos;

d) Entrevista devolutiva: após análise de cada depoimento, as bolsistas encontravam com cada sujeito individualmente para apresentar a análise construída sobre seu relato, a fim de que ele a confirmasse, modificasse ou desse sugestões de melhoria para o texto da análise individual;

e) Síntese final dos significados em comum: após possíveis modificações na análise de cada relato individual, 
a equipe de pesquisa em contexto de diálogo procurou o que de comum houve no conjunto total dos relatos.

\section{Resultados e discussão}

Ao buscar compreender os sentidos dados pelos sujeitos à experiência de participarem da oficina de desenvolvimento da escuta, percebemos que, dentre os resultados obtidos, estão os alcances terapêuticos (no sentido de mobilizações subjetivas; revelações e reflexões sobre si mesmo e suas relações interpessoais), principalmente para aqueles estudantes de períodos iniciais. Houve, inclusive, os que acreditaram que a oficina era um tipo de terapia em grupo:

Nunca fiz terapia, nem nada (...) Aquilo para mim foi, não sei... Não sei de nada. É complicado esse negócio de escutar o outro, porque realmente eu fui e acabei me escutando lá. Mas eu acho que eu precisava disso primeiro, para poder depois me pôr para o outro. (V, $2^{\circ}$ período)

Nunca tinha participado de terapia em grupo, eu achei divertido. Inicialmente pareceu uma proposta lúdica, mas o tempo todo a terapeuta tentou encaminhar a gente mais para o sentido de que tudo tem um sentido de ser. $\left(\mathrm{P}, 2^{\circ}\right.$ período)

Eu me senti cuidada a partir do momento em que eu podia me expressar, não sei... Eu refleti demais, eu chorava demais, era como se eu tivesse com uma coisa presa e depois tivesse um espaço em que eu pudesse falar. ( $\mathrm{G}, 3^{\circ}$ período)

Percebemos, com estes recortes de relatos, que a oficina vai favorecendo um desenvolvimento de escuta que se produz no ato de escutar-se a si a partir do escutar o outro e que isto ocorre devido um ambiente facilitador (conforme nomeia ROGERS, 1997) para o desabrochar de um processo de autodescoberta.

Percebemos, também, que, de um lado, estudantes em início de curso e que nunca passaram por uma psicoterapia individual ou de grupo não conseguem identificar a diferença entre um alcance terapêutico e um resultado psicoterapêutico; e, de outro, a necessidade premente dos estudantes de se submeterem a um processo de ajuda psicológica. Isto nos remete às ideias de Meira \& Nunes (2005), quando advertem que grande parte dos ingressantes nos cursos de graduação de Psicologia restringe a profissão à psicoterapia ou à psicologia clínica e que esta visão perdura por muito tempo ao longo da graduação.

No entanto, talvez essa sensação de se tratar de uma psicoterapia de grupo tenha sido uma consequência dos estudantes lidarem uns com os outros diariamente. A atmosfera que permeou o desenrolar de todas as oficinas foi de acolhimento e aceitação. Isto se comprova pela constatação de que, como resultados para a vida pessoal, alguns estudantes chegaram a apontar características individuais que eram expressas no grupo sem preconceitos, como nos falou P ( $3^{\circ}$ período): "Eu falo muito comigo e aí naquele dia eu encontrei um ambiente propício para isso e eu acho que o fato de ter pessoas íntimas também lá e muitas coisas influenciaram para me sentir mais afetada".

Já CC ( $4^{\circ}$ período) associa o ambiente acolhedor das diferenças individuais aos objetivos da própria oficina:

Acho que a oficina de escuta vem justamente para isso, para ajudar a abrir a nossa visão de que existem diferentes formas de dar a mão a esse sujeito, de vê-lo de várias formas, principalmente sem criticar, porque eu acho que o nosso mundo quer hoje uma forma de suprimir esse sujeito, não deixar ele vir a ser o que ele é. Então, a oficina deu liberdade para a gente poder não aprisionar esse sujeito, mas deixar ele vir como ele é. Eu acho que essa foi uma das coisas mais importantes. (CC, $4^{\circ}$ período)

Sendo assim, a oficina de desenvolvimento da escuta assumiu também uma função terapêutica, dada, sobretudo, à permissividade do ambiente - expressa na credibilidade e confiança enquanto funções facilitadoras -, o que é essencial para o processo de abertura à experiência por parte do sujeito, segundo Rogers (1997). Isto se reflete em boa parte das afirmações, as quais são exemplificadas nos trechos:

Eu tenho 'C' [aluna trainee], que conhece todo mundo no curso... As pessoas dão a segurança para você, querendo ou não. Então, o jeito de falar, o jeito físico, o jeito de se portar, a maneira de segurar na sua mão enquanto você estava ali... Essas coisas vão contando e pessoas que não ficam tão seguras, num ambiente como esse, acabam se deixando levar. $\left(\mathrm{O}, 2^{\circ}\right.$ período $)$

Eu acho que, como o ambiente estava muito diferente, era um clima em que o silêncio era muito respeitado, então quando alguém falava, a atenção ficava voltada para o que aquela pessoa estava falando. Deu realmente uma valorização no processo de falar e o de escutar. (Ax, $2^{\circ}$ período)

A coordenadora conduzia e fazia o ambiente ficar muito em paz e tranquilo de certa forma. Às vezes, você estava super aflorando, mas até isso era conduzido de uma forma tranquila, em que as pessoas podiam se expor sem vergonha. Era um momento que você podia se expor se fosse o caso, ou então ficar tranquilo só observando. Você não tinha uma obrigação de fazer alguma coisa, de ter uma resposta certa para o que estava acontecendo. Você podia estar no seu momento, só experienciando sem obrigações de uma coisa, de uma coisa certa, de trabalhar tudo certinho, dar uma resposta o mais rápido possível. ( $\mathrm{R}, 4^{\circ}$ período) 
As falas acima possibilitam compreender que houve um processo de escutar em que os participantes reconhecem os papeis dos facilitadores (traines e professora) de educarem os estudantes para ouvir e calar; escutar e ser escutado; e não emitir juízo de valor sobre o conteúdo da fala do outro.

Alguns estudantes, independente do período cursado, referiram-se a mudanças favoráveis nos processos pessoais, denotando um encontro consigo mesmo, uma mobilização subjetiva e uma apropriação de singularidade. G ( $3^{\circ}$ período) relata: “apesar de ser uma coisa importante para minha profissão, foi importante também para minha vida pessoal. As atividades que aconteceram então... Eu chorava muito e eu pensava. Aí me levou muito a refletir. Foi muito importante mesmo nesse sentido". Enquanto D ( $4^{\circ}$ período) nos diz:

Para mim foi uma experiência diferente e bastante proveitosa porque foi um momento que a gente teve de parar realmente em meio a tanta coisa da faculdade para fazer, e aquele momento de estar lá simplesmente para ouvir, para se deixar ouvir, para tentar entender a importância dessa ferramenta que é a nossa ferramenta de trabalho e que a gente se preocupa muito com teorias e acaba se esquecendo do básico, do principal que é ouvir.

Percebemos pelos trechos acima como o estudante reconhece a necessidade de um espaço acadêmico para além da sala de aula quando o tema é a escuta, denunciando, também, reflexões de como o cuidar de si e escutar é importante para a futura prática profissional. Houve, ainda, o reconhecimento da oficina como proporcionadora de reflexões e mobilizadora do sujeito. Neste sentido, surge a percepção da implicação e afetação na prática. O estudante passa a perceber não só a afetação recíproca, mas a necessidade de que ela ocorra para escutar (Amatuzzi, 1990).

Eu não tinha percebido o quão, o quão forte é a escuta e a fala, quando se trata de entender, ou de perceber o que é o outro ou o quão você está inserido no outro, e como o outro está inserido em você também, e aí quando foi passando os momentos lá, eu fui percebendo que a gente se encontra na fala da outra pessoa o tempo todo e a forma como essas histórias estão entrelaçadas e se entrelaçam a todo o tempo. (P, $4^{\circ}$ período)

O alcance das oficinas na vida pessoal dos acadêmicos repercutiu no desenvolvimento da escuta, pois mesmo esperando um processo mais técnico, surpreenderam-se positivamente com o direcionamento subjetivo, o que se confirma na seguinte fala:

Foi algo bem diferente, mostrou muito, eu entrei esperando que fosse aquela coisa mesmo de você aprender de forma mais técnica sobre escutar o outro, já que eu faço parte do curso de psicologia. Mas muito pelo contrário. No começo foi muito mais um escutar de si - eu lembro muito disso. Foi algo que trabalhou primeiro na gente e depois você passa a ter uma visão diferente de escutar o outro também. (Z, $4^{\circ}$ período)

Essa mobilização pessoal levou os participantes a se atentarem à noção de cuidado com o outro atrelado ao autocuidado e à afetação pessoal, o que faz parte do escutar, como diz Amatuzzi (1990). A respeito dessa questão, $\mathrm{P}\left(4^{\circ}\right.$ período) disse:

Hoje eu consigo compreender um pouco melhor o que é o humano e quais são os seus problemas e como lidar com suas angústias. E eu acho que até é um passo muito importante para a formação, a parte em que você se permite tocar pelo outro, mesmo com certo distanciamento profissional, sabe, a forma como eu me encontrei ali naquele espaço como, na fala dos outros, das outras pessoas (...) Isso me fez perceber que o humano é isso, é a união de coisas diferentes.

O relato acima possibilita pensarmos que a oficina permitiu um processo que se desdobrou para além dos encontros, considerando que as entrevistas ocorreram alguns meses após as oficinas, e que tal processo leva a reflexões sobre a formação e a prática profissional diante do cliente (um "outro" que não "eu”). No que tange aos resultados no âmbito acadêmico/profissional, alguns estudantes destacaram a escuta como uma ferramenta indissociável ao trabalho do psicólogo e como ela pode ser desenvolvida no decorrer da graduação. Segundo os participantes, a escuta passou a ser mais atenta e a oficina foi, em alguns casos específicos, norteadora para uma atuação mais efetiva no contexto de estágio no final do curso:

Eu levei muito mais para o âmbito profissional e que me leva ainda a refletir sobre algumas coisas, da prática do estágio, me leva a pensar e a me avaliar (...) Avaliar o instrumento de escuta a partir do que eu participei. (N, $9^{\circ}$ período)

Eu acredito que tenha me dado uma segurança um pouco maior. A gente fazia atividades com o próprio participante, muitas vezes era com a coordenadora auxiliando, outras vezes era sozinha e aquilo ali deu uma segurança maior. Eu acho que a oficina da escuta me ajudou bastante (...) Eu entrei no estágio um pouco mais segura do que se eu não tivesse tido essa oportunidade de iniciar com esses trabalhos. Eu acredito que eu tenha ficado mais segura, por mais que eu ainda tenha ficado muito nervosa, mas eu acho que entrei com um pouco mais de segurança. (A, trainee, $10^{\circ}$ período) 
O relato acima permite percebermos diferenças marcantes entre os processos dos participantes e o das trainees, já que para essas a experiência permitiu um aperfeiçoamento do fazer psicológico, talvez pelo fato da função de facilitadora que ocupava, viabilizando uma maior segurança diante das expectativas da futura prática profissional. Como diz Braga, Daltro e Danon (2012), a escuta é uma ferramenta indispensável no trabalho do psicólogo e se constitui como principal dispositivo de cuidado do profissional. As experiências dos sujeitos trouxeram essa questão, quando eles se referiram à oficina como marco para o despertar da consciência acerca da importância que a escuta tem no contexto pessoal e profissional.

Então você desperta um pouco para aquilo que de alguma forma você vai ser enquanto profissional e acho que perpassa até a nossa construção pessoal mesmo. Enquanto por ser do psicólogo, isso vai me modificando também, então acho que foi o primeiro ou um dos primeiros contatos e acho que foi uma preparação a mais, foi algo que não era previsto na minha grade curricular, mas que agregou valor mesmo à minha formação. (Z, $4^{\circ}$ período)

Pelo trecho de relato acima, podemos apontar outra característica que se afirmou como ganho para os estudantes, que foi o desenvolvimento da competência da escuta clínica, que não se dava necessariamente em sala de aula, através de teorias ou técnicas. Este aspecto despertou novos modos de subjetivação e o contato maior com a prática profissional vindoura, que envolve a escuta do outro. Corroborando com a ideia de Heckert (2007), o estudante pesquisado apresenta a necessidade de experienciar a escuta enquanto prática, além do ambiente acadêmico comum, para assim obter maior apropriação acerca da utilização desse dispositivo. Questionado se houve ganhos de aprendizagem após sua participação na oficina, um dos sujeitos responde:

Muito, muito... Eu acho que muito mais do que muitas coisas que eu já vi ao longo desses quatro períodos. Porque por mais que seja necessário esse oculozinho que é a teoria para a gente olhar a partir do nosso objeto de estudo, também é necessário não só os óculos como o que eu vou ouvir, como eu vou ouvir, que, às vezes, a gente se prende muito ao ouvir de acordo com a teoria e muita coisa passa despercebida. (CD, $4^{\circ}$ período)

As atividades desenvolvidas durante a oficina colocaram os participantes em contato com sua realidade no curso, gerando desdobramentos de significados para além do momento da sua realização, apontando para suas responsabilidades enquanto futuros profissionais e ratificando o amadurecimento ao revelar processos que já existiam no sujeito, mas dos quais este não tinha se apropriado:
“(...) A oficina da escuta foi bom por isso, porque me deu uma força, um olhar melhor para o curso. Acho que é isso" ( $\mathrm{S}, 4^{\mathrm{O}}$ período).

Os sujeitos descreveram, também, que, após sua participação na oficina, houve uma mudança na maneira de enxergar a escuta clínica, e a diferenciaram da escuta dita comum, a exemplo de $\mathrm{N}$ ( $9^{\circ}$ período): "Eu acho que a competência é a escuta em prática psicológica, entendeu? Que não é uma escuta comum. Aí, na prática psicológica eu acredito que deve haver esse distanciamento do que se fala para que não seja entendido de cara”. Outros ganhos de aprendizagem se referem à função humanizadora e acolhedora do eu que a oficina teve como experiência para os estudantes. Enquanto EM ( $4^{\circ}$ período) diz que "escutar já é um processo de mais cuidado, um processo em que você vai estar prestando mais atenção", $\mathrm{G}$ ( $3^{\circ}$ período) relata:

Essa questão mesmo de ver a seriedade do que a gente está fazendo aqui, eu como estudante, a seriedade de estar no curso e depois sair, trabalhar e estar só e ter a responsabilidade de lidar com vidas, com seres humanos, que não é qualquer coisa, ter uma visão mais humanizada assim das coisas; a questão do ouvir, de não só querer colocar o que eu acho, mas também ouvir o outro, aprender a ouvir.

Ao se depararem com uma escuta acolhedora, humanizada, sensível, uma escuta de si e do outro que promove cuidado, os sujeitos se mobilizavam. Esse foi o caso de CC ( $4^{\circ}$ período): "Com certeza a oficina de escuta ajuda principalmente a pessoa que está participando a se humanizar, porque o que mais vi foi essa forma de ajudar a acolher o outro".

O contato com o outro permitiu, também, o desenvolvimento de habilidades interpessoais que, segundo os psicólogos participantes do estudo de Bandeira et al. (2006), é algo que nem sempre ocorre num contexto de graduação em psicologia. Portanto, a oficina se mostra como fértil para o desenvolvimento de competências valorizadas como significativas para a futura atuação profissional, como, por exemplo: ouvir com atenção a fala de outro; expressar empatia; fazer relações entre diferentes conteúdos da fala do interlocutor; e interpretar a fala do outro. O recorte da entrevista de CD ( $4^{\circ}$ período) é bem característico disso:

Eu só fiquei me colocando no lugar dela... Pensando "meu Deus, que tenso" (...) Você fala, aí a outra pessoa não está fazendo nada, a outra pessoa só está fazendo com que você se escute, às vezes está repetindo até o que você disse... Porque, às vezes, até eu tinha consciência, não é questão de inconsciência do que diz, mas é um parar para perto da magnitude do que você fala, né? Foi bem tenso... 
Alguns participantes apontaram a oficina como algo novo na universidade, sendo, portanto, uma experiência única e significativa para eles. EM ( $4^{\circ}$ período) alegou que gostou muito de participar, na época ela "estava no segundo período e não tinha contato nenhum com uma das atividades que o psicólogo poderia estar exercendo”. ER ( $4^{\circ}$ período) também destacou a novidade, pois disse que "foi uma experiência nova dentro da faculdade" e importante porque "teve contatos com outras pessoas do curso que não conhecia”. AB ( $9^{\circ}$ período), além de revelar que "foi algo inédito dentro da UNIVASF", acrescenta que "nunca teve e sabe-se lá quando vai ter de novo oficinas realmente focadas na escuta”.

Estudantes de períodos mais adiantados sinalizaram a relevância da oficina na vida profissional como futuros psicólogos e muitos relataram a importância da escuta como competência a ser desenvolvida pelo profissional de psicologia, como pode se constatar abaixo:

Eu defino a escuta como a ferramenta do psicólogo: a ferramenta. Claro que nós temos outros dispositivos possíveis para trabalhar como psicólogos, mas a escuta é indispensável (...) É o ponto chave da nossa profissão: a escuta, o exercício da escuta. Então, passava pela minha cabeça: meu Deus será que vou ter mesmo a competência de estar fazendo esse exercício?! (AB, $9^{\circ}$ período)

Independente dos períodos que os alunos cursavam, para além da escuta clínica, eles se apropriavam de outras competências. No entanto, percebemos que os alunos mais novos tiveram mais abertura e disponibilidade ao participar das atividades sugeridas. Acreditamos que eles tiveram a escuta sensibilizada muito mais no que se refere ao âmbito pessoal enquanto que os veteranos destacaram a importância no âmbito profissional. Diante do que foi exposto, parece ter havido, portanto, unanimidade quanto à importância que a oficina de desenvolvimento da escuta teve para os estudantes. Desde os ganhos pessoais - que remetem às questões de autocuidado e escuta de si - aos profissionais e acadêmicos - voltados para o amadurecimento no curso e para a visão da futura prática profissional.

Outro dado constatado diz respeito ao contrato efetivado na oficina. Diversamente do que se poderia imaginar, mostrou-se como algo de extrema relevância para o desenvolvimento de algumas competências nos participantes, como, por exemplo, o sigilo e a pontualidade. Na observação da condução do processo, os estudantes conseguiram assimilar algumas ações que são intrínsecas à prática profissional, como cumprir com o horário estipulado para iniciar o atendimento ou a atividade programada, e o compromisso ético do sigilo do que é revelado no devir da atuação. Isto pode ser visto nas respostas de dois dos estudantes participantes e de uma trainee, quando questionados sobre o que foi assimilado da oficina e que eles poderiam utilizar na futura prática profissional:
"Eu não falava das outras para ela, eu só falava daquela mesmo que ela participou... É uma coisa minha, é uma coisa dela... Então ficou só entre nós duas mesmo.” (E, Trainee, $4^{\circ}$ período).

Acho que em primeiro lugar é o sigilo. A gente tinha a certeza do sigilo. "Vai sair daqui e vocês não vão poder sair falando e tal”, ponto! Isso foi posto na primeira conversa que a gente teve da oficina. $\left(0,2^{\circ}\right.$ período)

Eu lembro que é uma coisa que é minha, a professora também sinalizou isso e aí eu coloco isso como uma competência que é a questão da pontualidade. Eu acho que é a própria responsabilidade profissional, não deixa de ser uma competência. (AB, $9^{\circ}$ período)

No que tange às experiências das trainees, participar das oficinas permitiu uma apropriação e uma relação melhor com o curso de Psicologia, pois possibilitou a elas experimentarem a prática da atuação do psicólogo:

Eu estava me dedicando ao curso, mas ainda não estava visualizando nada prático, o que é que eu ia fazer com isso depois, mas quando surgiu a oportunidade de participar desse projeto de extensão eu pude ver o que é que é que eu estava fazendo ali no curso. Até então eu estava meio navegando assim, eu sabia que eu ia chegar na praia, como se eu tivesse no mar, eu não estava nadando aleatoriamente para qualquer lado, eu sabia que eu ia chegar na praia, mas eu não sabia como era essa praia, entendeu? E a oficina de desenvolvimento da escuta me possibilitou ver que praia era essa que eu ia chegar e eu gostei do que eu vi (...). Participar da oficina me ensinou, me despertou, me sensibilizou muito essa escuta diferenciada que eu acho que não é uma escuta comum e ao mesmo tempo também me jogou nessa experiência de estar lá, de escutar o outro, de ver como aquilo estava acontecendo, de como um psicólogo deve mediar aquele processo grupal. (...) Quando eu cheguei na disciplina de processos grupais eu cheguei um pouquinho melhor por ter vivenciado aquilo, então quando a gente estudou, por exemplo, reações $G$, eu já lembrava muito, me remetia muito à oficina, por ter tido essa experiência prática antes da aula teórica, isso me ajudou muito a chegar na aula teórica mais apropriada. (C, Trainee, $4^{\circ}$ período)

No caso de uma trainee, em específico, a oficina foi crucial para a escolha do tema a ser pesquisado no Trabalho de Conclusão de Curso, e explicita a importância da oficina também como atividade acadêmico-científica:

Então eu acho que ela foi tão tão significativa para mim que de repente eu escolhi querer pesquisar, fazer o meu trabalho de conclusão de curso a partir dessa temática da escuta. E, com certeza, foi o pontapé essas oficinas, 
essa experiência que eu tive foi o pontapé para que eu pudesse desenvolver esse trabalho. (A, Trainee, $10^{\circ}$ período)

Por fim, percebemos que as entrevistas, ao revisitarem as oficinas, proporcionaram mudanças, reflexões e novos modos de subjetivação aos participantes, o que cumpre com a natureza mesma da pesquisa fenomenológica, como nos apresenta Amatuzzi (2008, p. 61):

Quando o interlocutor (pesquisado) assume a mesma intenção de pesquisa que o pesquisador, ele sai beneficiado por ela. Ele sai compreendendo-se melhor (e capaz de ações mais efetivas). Por isso, dentro da luz fenomenológica, não há diferenças essenciais entre pesquisa e atendimento psicológico ou psicoterapia. A aproximação do vivido desencadeia mudanças.

O trecho da entrevista com um dos integrantes da equipe de pesquisa e uma participante da oficina a seguir serve para ilustrar o que afirmou Amatuzzi e nos permite concluir que a condução de uma pesquisa sobre o vivido está claramente associada com mudanças em modos de subjetivação, denotando como o presente estudo pôde, também, ser significativo para o desenvolvimento da escuta do estudante, principalmente para os orientandos da pesquisa, que, por sinal, também foram os trainees.

(CD, $4^{\circ}$ período): Eu falei para você, naquele dia que foi as frases lá na parede quando a gente voltou, porque ali ficou muito bem que muita coisa tinha sido dita pelas pessoas e que eu não tinha escutado... e aí na hora que eu cheguei as coisas estavam ali e eu só reconheci uma frase que tinha sido minha... as outras eu não tinha reconhecido... eu estava ao lado de Z e ela falou "ah aquilo não sei que...”, aí eu comecei a perceber que aquilo não era só a minha frase, tinha frase de todo mundo e que eu não tinha escutado metade daquilo ali, mas a minha eu lembrava... aí foi a parte que eu gostei muito...

\section{E isso te diz alguma coisa sobre a sua escuta?}

(CD, $4^{\circ}$ período) Diz... só comprova o quanto eu, às vezes, a pessoa só ouve né? entra por aqui sai por ali ou nem entra às vezes. Sim, talvez a gente estivesse só preocupada na hora do que eu ia falar, o que que eu ia falar, e deixou passar muita coisa do que estava sendo dito numa oficina que era de escuta.

\section{Considerações finais}

Diante dos resultados obtidos pelos estudantes que participaram de oficinas de desenvolvimento da escuta, defendemos que elas podem configurar uma modalidade de prática clínica em psicologia organizacional e do trabalho a ser adotada em instituições de ensino su- perior que ofereçam o curso em questão. Tal prática clínica pode permitir, como se viu na presente pesquisa, a transformação em modos de subjetivação de aprendizes, favorecendo crescimento pessoal, apropriação e desenvolvimento de competências para o futuro ingresso no mercado de trabalho.

Interessante destacar que, embora as oficinas tenham sido conduzidas pelo viés da psicologia humanista, em nenhum relato recolhido os estudantes destacaram a abordagem em questão ou se referiram a ela como condição para o desenvolvimento da escuta. Nesse sentido, a oficina pode beneficiar todos os estudantes independente da abordagem teórico-prática com a qual esse ou aquele graduando possa se identificar ou vir a praticar em seu estágio de final de curso ou em sua futura atuação como psicólogo.

Como o estudo foi realizado em apenas uma instituição, sugerimos a condução das oficinas em outros contextos acadêmicos para que tal modalidade possa ser institucionalizada como uma prática significativa para o cumprimento das Diretrizes Curriculares Nacionais, já que estas defendem atividades que extrapolem a sala de aula e contribuam para o desenvolvimento de competências no graduando de psicologia. Além disso, propomos pesquisas longitudinais com maior tempo de oficina, comparando a sensibilização e o desenvolvimento da escuta em alunos de diferentes períodos, visto que o fato de estarem mais próximos ou mais distantes do momento de adentrarem o estágio no final do curso tem repercussões no modo como os estudantes vivenciam e assimilam as atividades propostas na oficina.

Enfim, esperamos que este estudo possa fomentar novos projetos de ensino, pesquisa e extensão, permitindo que os educadores, formadores de psicólogos, cumpram seu compromisso de agentes de transformação de realidades sociais e sua missão de escutar e cuidar de seus aprendizes.

\section{Referências}

Amatuzzi, M. M. (1990). O que é ouvir. Estudos de Psicologia, 7(2), 86-97. Recuperado em 19, março, 2014 de <https:// scholar.google.com/scholar_lookup?title $=\mathrm{O}+$ que $+\%$ C3\% A9+o+ouvir\&author $=$ Amatuzzi + M. + M.\&publication_ye ar $=1990 \&$ journal $=$ Estudos + de + Psicologia\&volume $=7 \&$ is sue $=2 \&$ pages $=86-97>$.

Amatuzzi, M. M. (2008). Por uma psicologia humana. São Paulo: Editora Alínea.

Bandeira, M., Quaglia, M. A. C., Freitas, L. C., Souza, A. M., Costa, A. L. P., Gomides, M. M. P., Lima, P. B. (2006). Habilidades interpessoais na atuação do psicólogo. Interação em Psicologia, 10(1), 139-149. Recuperado em 21, agosto, 2013 de $<$ https://www.researchgate.net/profile/Marina_Bandeira/ publication/273428452_Habilidades_interpessoais_na_atuacao_do_psicologo/links/5677eaba08aebcdda0eb9d1̄a.p̄ff $>$. 
Bicudo, M. A. V., Martins, J. (1989). A pesquisa qualitativa em psicologia. Fundamentos e recursos básicos. São Paulo: Moraes/EDUC.

Braga, A. A. N. M., Daltro, M. R., \& Danon, C. A. F. (2012). A escuta clínica: um instrumento de intervenção do psicólogo em diferentes contextos. Revista Psicologia, Diversidade e Saúde, 1(1), 87-100. Recuperado em 12, setembro, 2013 de <https://www5.bahiana.edu.br/index.php/psicologia/ article/view/44>.

Brasil, CNE/CES (2011). Resolução N. 5, de 15 de março. Recuperado em 12, setembro, 2014 de < http://portal.mec.gov.br/ index.php?option=com_content\&id $=12991>$.

Coelho, N. E., \& Figueiredo, L. C. (2004). Figuras de intersubjetividade na constituição subjetiva: dimensões da alteridade. Interações, 9(17), 9-28. Recuperado em 22, agosto, 2014 de <http://pepsic.bvsalud.org/scielo.php?pid=S1413$-29072004000100002 \&$ script $=$ sci_arttext $>$.

Giorgi, A. (1985). Phenomenology and psychological research. Pittsburg: Duquesne University Press.

Heckert, A. L. C. (2007). Escuta como cuidado: o que se passa nos processos de formação e de escuta? Em R. Pinheiro, R. A. de Mattos (Orgs.), Razões públicas para a integralidade em saúde: o cuidado como valor (pp. 199-212). Rio de Janeiro: ABRASCO/CEPESC.

Lima, D. (2005). Algumas considerações sobre a escuta na abordagem fenomenológico-existencial. Recuperado em 03, maio, 2012, de <http:/portalamazonia.globo.com/plantaopsicologico/algumasconsideracoesescuta.pdf $>$.

Macêdo, S.M. (2000). Psicologia clínica e aprendizagem significativa: relatando uma pesquisa fenomenológica colaborativa. Psicologia em Estudo, 5(2), 49-76. Recuperado em 25, abril, 2013, de <http://www.scielo.br/scielo.php?script=sci_artt ext\&pid $=$ S1413-73722000000200005 $>$.

Macêdo, S.M.V.M. (2006). Condições de trabalho e saúde mental entre profissionais de psicologia na região metropolitana do Recife: um estudo fenomenológico. Travessia, VIII(1), pp. 141-158.

Macêdo, S., \& Caldas, M. T. (2013). Merleau-Ponty e Gadamer: possibilidade de se pesquisar a prática de psicólogos clínicos. Em L. C. Barreto, H. T. Morato, \& M. T. Caldas (Orgs.), Prática psicológica na perspectiva fenomenológica (pp. 183201). Curitiba: Juruá.

Meira, C. H. M. G., \& Nunes, M. L. T. (2005). Psicologia clínica, psicoterapia e o estudante de psicologia. Paideia, 15(32), 339-343. Recuperado em 12, julho, 2014 de <http:// www.scielo.br/scielo.php?script $=$ sci_arttext\&pid $=$ S0103$-863 X 2005000300003>$.

Quayle, J. (2010). Reflexões sobre a formação do psicólogo em psicoterapia: estado da arte e desafios. Psicologia: Ensino \& Formação, 1(1): 99-110. Recuperado em 18, novembro, 2013 de <http://pepsic.bvsalud.org/scielo.php?pid=S2177$-20612010000100009 \&$ script $=$ sci_abstract $>$.

Rogers, C. (1997). Tornar-se pessoa. São Paulo: Martins Fontes.
Aíla Matos Dourado - Psicóloga graduada pela Universidade Federal do Vale do São Francisco.

Cristiane Alves Quirino - Graduanda em Psicologia pela Universidade Federal do Vale do São Francisco.

Monzitti Baumann de Almeida Lima - Graduando em Psicologia pela Universidade Federal do Vale do São Francisco.

Shirley Macêdo Vieira de Melo - Mestre em Psicologia Clínica pela Pontifícia Universidade Católica de Campinas, Doutora em Psicologia Clínica pela Universidade Católica de Pernambuco e Professora Adjunto da Fundação Universidade Federal do Vale do São Francisco (UNIVASF). Endereço Institucional: Av. José de Sá Maniçoba, s/n, Centro, Petrolina/ PE, CEP: 56304-917. E-mail: mvm.shirley@gmail.com

Recebido em 25.11.2015 Primeira Decisão Editorial em 21.02.2016 Aceito em 12.05.2016 